\title{
15-deoxy- $\Delta^{12,14}-$ PGJ $_{2}$ induces synoviocyte apoptosis and suppresses adjuvant-induced arthritis in rats
}

\author{
Yutaka Kawahito, ${ }^{1}$ Motoharu Kondo, ${ }^{1}$ Yasunori Tsubouchi, ${ }^{1}$ \\ Akira Hashiramoto, ${ }^{1}$ David Bishop-Bailey, ${ }^{2}$ Ken-ichiro Inoue, ${ }^{1}$ \\ Masataka Kohno, ${ }^{1}$ Ryoji Yamada, ${ }^{1}$ Timothy Hla, ${ }^{2}$ and Hajime Sano ${ }^{1}$ \\ ${ }^{1}$ First Department of Internal Medicine, Kyoto Prefectural University of Medicine, Kyoto, Japan \\ ${ }^{2}$ Center for Vascular Biology, Department of Physiology, University of Connecticut School of Medicine, \\ Farmington, Connecticut, USA \\ Address correspondence to: Yutaka Kawahito, First Department of Internal Medicine, Kyoto Prefectural \\ University of Medicine, 465 Kajii-cho, Kamigyo-ku, Kyoto 602-8566, Japan. Phone: 81-75-251-5505; \\ Fax: 81-75-252-3721; E-mail: kawahity@cam.hi-ho.ne.jp. \\ David Bishop-Bailey's present address is: Department of Cardiovascular and Inflammation Research, William Harvey \\ Research Institute, St. Bartholomew's and the Royal London School of Medicine and Dentistry, London, United Kingdom.
}

Received for publication February 21, 2000, and accepted in revised form June 6, 2000.

\begin{abstract}
Peroxisome proliferator-activated receptors (PPARs) are members of the nuclear hormone receptor superfamily and have a dominant regulatory role in adipocyte and monocyte differentiation. PPAR- $\gamma$ agonists are also negative regulators of macrophage activation and have modulatory effects on tumorigenesis. In this study we demonstrate that synovial tissue localized expression of PPAR- $\gamma$ in patients with rheumatoid arthritis (RA). We detected markedly enhanced expression of PPAR- $\gamma$ in macrophages, as well as modestly enhanced expression in the synovial lining layer, fibroblasts, and endothelial cells. Activation of the PPAR- $\gamma$ by 15-deoxy- $\Delta^{12,14}$-prostaglandin $\left.\mathrm{J}_{2}(15 \mathrm{~d}-\mathrm{PGJ})_{2}\right)$ and the synthetic PPAR- $\gamma$ ligand (troglitazone) induced RA synoviocyte apoptosis in vitro. Moreover, intraperitoneal administration of these PPAR- $\gamma$ ligands ameliorated adjuvant-induced arthritis with suppression of pannus formation and mononuclear cell infiltration in female Lewis rats. Antiinflammatory effects of $15 \mathrm{~d}-\mathrm{PGJ}_{2}$ were more potent than troglitazone. These findings suggest that PPAR- $\gamma$ may be an important immunoinflammatory mediator and its ligands, especially $15 \mathrm{~d}-\mathrm{PGJ} \mathrm{J}_{2}$, may be useful in the treatment of RA.
\end{abstract}

J. Clin. Invest. 106:189-197 (2000).

\section{Introduction}

Rheumatoid arthritis (RA) is a chronic, destructive inflammatory polyarticular joint disease, characterized by massive synovial proliferation and subintimal infiltration of inflammatory cells, along with angiogenesis $(1,2)$. The inflammation of RA results in the production of prostaglandins (PGs) $\mathrm{E}_{2}$, cytokines, and nitric oxide $(1,3)$. In particular, macrophage-derived cytokines such as TNF- $\alpha$ (4) and IL-1 (5), which are abundant in synovial tissues and fluid from patients with RA, are mitogens for synovial fibroblasts, as well as osteoclasts. Blocking of these cytokines inhibits the release of synovial production of other proinflammatory cytokines. This suggests that TNF- $\alpha$ and IL- 1 are key proinflammatory molecules in cytokine cascade in RA. In fact, TNF- $\alpha$ receptor antagonists, neutralizing antibodies against TNF- $\alpha$, and IL- 1 receptor antagonist can control joint inflammation in most RA patients (6-8). Moreover, the formation of active inflamed pannus is thought to be critical for erosive disease and results in irreversible destruction of the cartilage and bone in affected joints. The mechanism responsible for synovial hyperplasia leading to pannus formation may be due to reduced apoptosis of inflam- matory cells and tumor-like synoviocytes $(9,10)$. Therefore, suppression of the production of inflammatory molecules and formation of hyperplastic synovium may be important targets of therapy for RA.

Peroxisome proliferator-activated receptors (PPARs) are members of the nuclear hormone receptor superfamily of ligand-activated transcriptional factors that include receptors for steroids, thyroid hormone, vitamin $\mathrm{D}$, and retinoic acid (11). PPAR binds to peroxisome proliferator responsive element (PPRE) as a heterodimer with the retinoic receptor (RXR), implying a role of 9-cis retinoic acid in the regulation of PPAR target genes (12, 13). To date, three mammalian PPAR subtypes have been isolated and termed PPAR- $\alpha$, NUC1 (also known as PPAR- $\delta)$, and PPAR- $\gamma(11,14,15)$. PPAR- $\alpha$ is highly expressed in the liver, heart, kidney, muscle, brown adipose tissue, and gut, which exhibit high carbolic rates of fatty acids $(14,16)$. PPAR- $\delta$ may be expressed ubiquitously, and its function is relatively unknown (17). Recent studies suggest that PPAR- $\delta$ may be a target for nonsteroidal anti-inflammatory drug-induced (NSAIDinduced) tumor suppression in colorectal tumors (18). PPAR- $\gamma$ is expressed at high levels in adipose tissue and is a critical regulator of adipocyte differentiation (19). 
In addition, PPAR- $\alpha$ and PPAR- $\gamma$ have been suggested to be important immunomodulatory factors (20). PPAR- $\alpha$-knockout mice exhibit exacerbated inflammatory responses, and leukotriene B4, a chemotactic mediator, seems to regulate the clearance of itself as an agonist of PPAR- $\alpha$ (21). PPAR- $\gamma$ is also expressed in the immune system, such as the spleen (16), monocytes, bone-marrow precursors (22), and helper T-cell clones (23). Recent data have shown that the natural PG, 15deoxy- $\Delta^{12,14}$-prostaglandin $\mathrm{J}_{2}\left(15 \mathrm{~d}-\mathrm{PGJ}_{2}\right)$, and synthetic anti-diabetic thiazolidinedione, which are PPAR- $\gamma$ ligands, lead to inhibition of phorbol ester-induced nitric oxide and macrophage-derived cytokines, i.e., TNF- $\alpha$, IL-1, and IL- 6 . These PPAR- $\gamma$ ligands inhibit gene expression in part by antagonizing the activities of the transcription factors such as AP- 1 and NF- $\mathrm{KB}$ $(24,25)$. Moreover, PPAR- $\gamma$ ligands, including troglitazone (anti-diabetic thiazolidinedione) and $15 \mathrm{~d}_{-} \mathrm{PGJ}_{2}$, have potent tumor modulatory effects against colorectal, prostate, and breast cancer (26-28). They also induce apoptosis in macrophages, fibroblasts, and endothelial cells (29-31).

The dietary supplementation of fish oil, including highly polyunsaturated fatty acids that can bind directly to PPAR- $\alpha$ and PPAR- $\gamma(32)$, results in significant improvement in tender joints and other clinical parameters of disease activity in RA $(33,34)$. NSAIDs inhibit synthesis of PGs and are widely used for treatment of RA. PPAR- $\alpha$ and $-\gamma$ are also activated by indomethacin and other NSAIDs at high doses (35). Because NSAIDs work better at higher doses than those required for inhibition of cyclooxygenase (COX) in RA (36), some of the actions of NSAIDs are thought to be mediated not only through inhibition of COX, but also through activation of PPARs. Moreover, IL-4, which is one of the Th2 cytokines with anti-inflammatory effects in RA (37), induces PPAR- $\gamma$ expression in macrophages (38). These findings suggest that PPAR $-\gamma$ may negatively regulate the inflammatory processes in RA.

In this study, we determined the expression of PPAR$\gamma$ on synovial tissues and cultured synoviocytes in patients with RA. We also demonstrated the effect of growth-inhibitory effects of troglitazone and $15 \mathrm{~d}-\mathrm{PGJ}_{2}$ and whether these PPAR- $\gamma$ ligands have potency in suppressing chronic inflammation and pannus formation of adjuvant-induced arthritis (AIA) in female Lewis rats.

\section{Methods}

Materials. Troglitazone was obtained from Sankyo Co., Ltd. (Tokyo, Japan) and $15 \mathrm{~d}_{-} \mathrm{PGJ}_{2}$ was purchased from Cayman Chemical (Ann Arbor, Michigan, USA). $\mathrm{PGE}_{2}$ and $\mathrm{PGF}_{2 \alpha}$ were from Sigma Chemical Co. (St. Louis, Missouri, USA). Antibody against human PPAR- $\gamma$ was from Santa Cruz Biotechnology Inc. (Santa Cruz, California, USA), anti-macrophage (CD68) antibody was from DAKO Japan (Kyoto, Japan). Control normal goat serum was from Vector Laboratories (Burlingame, California, USA), and mouse immunoglobulin G3 $\kappa$ was from Biogenesis (Poole, United Kingdom).
Tissue specimens and synovial cell preparation. Synovial tissues were obtained during replacement surgery from patients with RA $(n=20)$ and osteoarthritis (OA) $(n=$ 10), according to criteria of the American College of Rheumatology. Synovial samples were obtained from the knee, elbow, and hip joint. Synovial tissues from RA were minced and stirred with $1 \mathrm{mg} / \mathrm{mL}$ collagenase (Sigma Chemical Co.) in serum-free RPMI-1640 (Nissui, Tokyo, Japan) for 3 hours, filtered through a nylon mesh, and washed extensively. Cells were cultured in RPMI-1640 supplemented with 10\% FCS (BioWhittaker, Walkersville, Maryland, USA) and $1 \%$ antibiotics (BioWhittaker) in a humidified incubator at $37^{\circ} \mathrm{C}$ in the presence of $5 \% \mathrm{CO}_{2}$. The synovial cells used were from passage 3-9, when they showed fibroblastoid morphology. Adipose tissues surrounding joints were used as positive controls for RT-PCR and Western blot analysis and were obtained from joint replacement surgery of RA patients, as well.

Immunostaining. Synovial tissue specimens were preserved in $10 \%$ formalin and embedded in paraffin, serially sectioned onto microscope slides at a thickness of 4 $\mu \mathrm{m}$, and then deparaffinized. Cultured synoviocytes were fixed with acetone for 30 seconds. Immunohistochemical staining was performed with the VectoStain avidinbiotin peroxidase complex kit (Vector) as described previously (39). Primary antibodies against human PPAR- $\gamma$ (1:100 dilution, in PBS) and control normal goat serum was used. In double-antibody immunostaining, tissue specimens were stained with anti-PPAR- $\gamma$ antibody (1:100 dilution, in PBS) using the alkaline phosphatase method and with anti-macrophage antibody $(50 \mu \mathrm{g} / \mathrm{mL})$ using the peroxidase method (39). Positive staining was indicated by brownish-black deposits for the peroxidase method, red deposits for the alkaline-phosphatase method, and black-red deposits for the double antibody-staining method. The sections were counterstained with $0.5 \%$ light-green SF yellowish (Sigma Chemical Co.).

Immunohistochemical analysis. For each of the tissue specimens from RA and OA, the extent and intensity of staining with anti-PPAR- $\gamma$ antibody in synovial lining cells, macrophages, endothelial cells, and fibroblasts were graded on a scale of $0-4+$ by two blinded observers on two separate occasions using coded slides as previously described (39). A 4+ grade implies maximally intense staining, whereas 0 implies no staining.

RNA preparation and analysis. Total cellular RNA was isolated from synoviocytes and fatty tissues in patients with RA $(n=5)$ by the acid guanidinium thiocyanatephenol-chloroform method. RT-PCR reactions were performed as described previously (40). The primers used were: (a) human PPAR- $\gamma$ (41), sense $5^{\prime}$-CAATCGAGCTGTCAAGAGAGC- $3^{\prime}$ and antisense 5'-GGAAGAAAT CCAAGGGCTGAG-3'; (b) G3PDH (40), sense 5'-CCACCCATGGCAAATTCCATGGCA- $3^{\prime}$ and antisense $5^{\prime}$-TCTAGAGGGCAGGTCAGGTCCACC- $3^{\prime}$. The conditions for thermal cycling were as follows: $94^{\circ} \mathrm{C}$ for 45 seconds, $52^{\circ} \mathrm{C}$ for 45 seconds, and $72^{\circ} \mathrm{C}$ for 2 minutes for 40 cycles. This program was preceded by 5 minutes at the 
given denaturation temperature and followed by 7 minutes at $72^{\circ} \mathrm{C}$. The amplification reactions were analyzed on $2.0 \%$ agarose gels.

Western blot analysis of PPAR- $\gamma$. Western blot analysis was performed to determine PPAR- $\gamma$ protein expression as described previously (42). Total protein extract from patients with RA $(n=5)$ and fat tissue was analyzed on blots incubated for 1 hour at room temperature with 1:200 dilution of goat anti-PPAR- $\gamma$ antibody (Santa Cruz Biotechnology Inc.), washed, and subsequently incubated for 1 hour at room temperature with horseradish peroxidase-linked rabbit anti-goat IgG (1:1500 dilution; EY Laboratories Inc., San Mateo, California, USA). After being washed again, blots were analyzed using an Amersham enhanced-chemiluminescence (ECL) system (Amersham Pharmacia Biotech, Buckinghamshire, United Kingdom), and exposed to Hyperfilm (Amersham Pharmacia Biotech) for 30 seconds to 5 minutes, resulting in adequate exposure to visualize the bands.

Cell-proliferative studies. RA synoviocytes $\left(5 \times 10^{3}\right.$ in media, $n=5$ ) placed onto $8 \times 8$-mm multichamber slides (Nunc, Copenhagen, Denmark) were treated with troglitazone $(1-50 \mu \mathrm{M}), 15 \mathrm{~d}-\mathrm{PGJ}_{2}(1-20 \mu \mathrm{M}), \mathrm{PGE}_{2}(20 \mu \mathrm{M})$, and $\operatorname{PGF}_{2 \alpha}(20 \mu \mathrm{M})$. Cell viability was measured at day 1 by a microplate reader using a modified 3-[4,5dimethylthiazol-2-thiazolyl]-2,5-diphenyltetrazolium bromide (MTT) assay (40) (WST-1 assay; Dojindo, Kumamoto, Japan), and presented as the percentage of control-culture conditions.

Detection of synovial apoptosis. DNA chromatin morphology was assessed using HOECHST staining (40). Synoviocytes were incubated with $30 \mu \mathrm{M}$ of troglitazone or $20 \mu \mathrm{M}$ of $15 \mathrm{~d}-\mathrm{PGJ}_{2}$ for 24 hours. Cells were washed by RPMI-1640 and labeled with $8 \mathrm{mg} / \mathrm{mL}$ of HOECHST 33342 (Sigma Chemical Co.) for 10 minutes; propidium iodide (Sigma Chemical Co.) was added $(10 \mathrm{mg} / \mathrm{mL}$ final concentration), and the cells were examined by fluorescence microscopy as described previously (40).

Adjuvant-induced arthritis in rats. Nine-week-old female Lewis rats were obtained from Charles River Japan (Yokohama, Japan). CFA was prepared by suspending heat-killed Mycobacterium butyricum (Difco Laboratories, Detroit, Michigan, USA) in liquid paraffin at 12 $\mathrm{mg} / \mathrm{mL}$. CFA-induced arthritis was stimulated by injection of $50 \mu \mathrm{L}$ of the CFA emulsion intradermally at the base of the tail, as described previously $(39,43)$. Treatment commenced at the onset of the disease; $15 \mathrm{~d}-\mathrm{PGJ}_{2}$ ( 2 times a day) and troglitazone (once a day) were intraperitoneally administered at the specified dose, respectively, until 10 days after onset of arthritis. 15d$\mathrm{PGJ}_{2}$ was diluted in PBS and troglitazone was freshly suspended in $0.3 \%$ carboxymethyl cellulose (CMC) PBS. In each experiment, a group of rats was injected with PBS or $0.3 \%$ CMC PBS, which served as a control. From day 8 after immunization (onset of arthritis), rats were examined daily for AIA using two clinical parameters, paw swelling and clinical score. The footpad volume was measured with a water replacement plethysmometer (Unicom Japan, Tokyo, Japan).
For clinical evaluation of AIA, we used a scoring system as follows: mid-forepaw, wrist, joints of finger, midfoot, ankle, and joints of digits, were scored 0 to 4 : 0 , normal; 1 , minimal swelling; 2 , medium swelling; 3 , severe swelling; 4, severe and non-weight-bearing arthritis. Each limb was graded, resulting in a maximal clinical score of 48 per animal.

For histological evaluation, we performed hematoxylin and eosin (H\&E) staining of tissue specimens of ankle, liver, and kidney. Two blinded observers evaluated cartilage and bone destruction by pannus formation and mononuclear cell infiltration in synovial tissues on two separate occasions, using the following scoring system (44): cartilage and bone destruction by pannus formation: 0 , no change; 1 , mild change (pannus formation within cartilage); 2 , moderate change (pannus invasion into cartilage/subchondral bone); 3 , severe change (pannus invasion into the subchondral bone); mononuclear cell infiltration: 0 , no infiltration; 1 , mild infiltration; 2 , moderate infiltration; 3 , severe infiltration.

Statistical analysis. The Mann-Whitney U test to compare nonparametric data for statistical significance was applied on the analysis of histological examination, paw volume of hindlimbs, and clinical score of arthritis.

\section{Results}

PPAR expression of synovial tissues and cultured synoviocytes. To examine the expression and localization of PPAR- $\gamma$ in synovial tissues of RA and OA, immunohistochemistry was performed. In all subjects from patients with RA (20 of 20) and OA (10 of 10), PPAR- $\gamma$ was expressed in synovial tissues. In RA we found markedly enhanced expression of PPAR- $\gamma$ in macrophages (immunohistochemical score, mean \pm SD: $3.1 \pm 0.7$ ) and moderate expression in synovial cells $(2.9 \pm 0.8)$, endothelial cells $(2.1 \pm 0.7)$, and fibroblasts $(2.6 \pm 0.7)$ (Figure 1, a and c). PPAR- $\gamma$ in macrophage-like cells was strongly localized in the perinuclear and cytoplasmic regions, but not in the nucleus. In OA the localization of PPAR- $\gamma$ in synovial tissues is almost the same as that in RA (Figure 1d). However, immunohistochemical score of PPAR- $\gamma$ in synovial lining cells $(1.0 \pm 0.7)$, macrophages $(0.7 \pm 0.6)$, endothelial cells $(1.3 \pm 0.7)$, and fibroblasts $(1.3 \pm 0.7)$ in OA was significantly smaller than those in $\mathrm{RA}(P<0.01)$. Immunostaining with normal goat serum was completely negative in all subjects from RA (Figure 1b) and OA (data not shown). Immunostaining with anti-PPAR- $\gamma$ antibody absorbed with synthetic PPAR- $\gamma$ polypeptide was also negative (data not shown).

To confirm the expression of PPAR- $\gamma$ in macrophages, we immunostained the same sections from the synovial tissue specimens of RA by a double antibody-staining method with anti-macrophage antibody and anti-PPAR- $\gamma$ antibody. Intense black-red deposits (double-positive cells) were detected in macrophages (Figure 1e). Control staining with normal goat $\mathrm{IgG}$ or mouse $\mathrm{IgG}_{3} \mathrm{~K}$ was uniformly negative (data not shown). These observations suggest that PPAR- $\gamma$ is localized in macrophages in synovial tissues. 


\section{Figure 1}

Immunostaining for PPAR- $\gamma$ in synovial tissues from RA and OA. (a-c, e) Synovial tissues from RA. (d) Synovial tissues from OA. Synovial tissue sections were stained with goat anti-PPAR- $\gamma(\mathbf{a}, \mathbf{c}$, d) antibodies and a normal goat $\lg G(\mathbf{b})$. Tissues seen in $\mathbf{a}, \mathbf{b}$, and c are derived from different patients. Positive immunostaining was indicated by brownish deposits. In double immunostaining for macrophage and PPAR- $\gamma(\mathbf{e})$, sections were stained with anti-PPAR- $\gamma$ antibody using alkaline phosphatase method (red deposits) and anti-human macrophage using antibody peroxidase method (brownish-black deposits). Double-positive staining cells were indicated by black-red deposits. Counter staining was done with $0.5 \%$ light-green SF yellowish. $\times 100$ (a-d); $\times 200$ (e). SL, synovial lining cell; BV, blood vessel; M, macrophage; F, fibroblast.

We also detected the expression of PPAR- $\gamma$ in cultured synoviocytes. The intensity and cellular localization of PPAR- $\gamma$ in cultured synoviocytes were almost the same as those of synovial lining cells in tissues. In culture, immunostaining of PPAR- $\gamma$ varied in that some synoviocytes had a predominantly cytoplasmic expression, whereas others had both cytoplasmic and nuclear expression (Figure 2a). However, treatment with $10 \mu \mathrm{M}$ of $15 \mathrm{~d}-\mathrm{PGJ}_{2}$ for 12 hours resulted in nuclear translocation of PPAR- $\gamma$ (Figure $2 \mathrm{~b}$ ).

PPAR- $\gamma m R N A$ and protein expression in synoviocytes. We next determined the expression of PPAR- $\gamma$ mRNA and protein in cultured synoviocytes from RA patients $(n=5)$ using RT-PCR and Western blot analysis. Amplification of $\mathrm{cDNA}$ with PPAR- $\gamma$ primers used in this study predicted a fragment of $474 \mathrm{bp}$ in length. The predicted band size was detected in cultured synoviocytes after amplification of reverse-transcribed mRNA in all subjects (5 of 5) and was also detected in adipose tissue (Figure 3a). Negative controls, performed with no RNA or no reverse transcriptase in the reverse transcription reaction yielded no detectable bands (data not shown). Primers specific for human G3DPH generated the expected 598
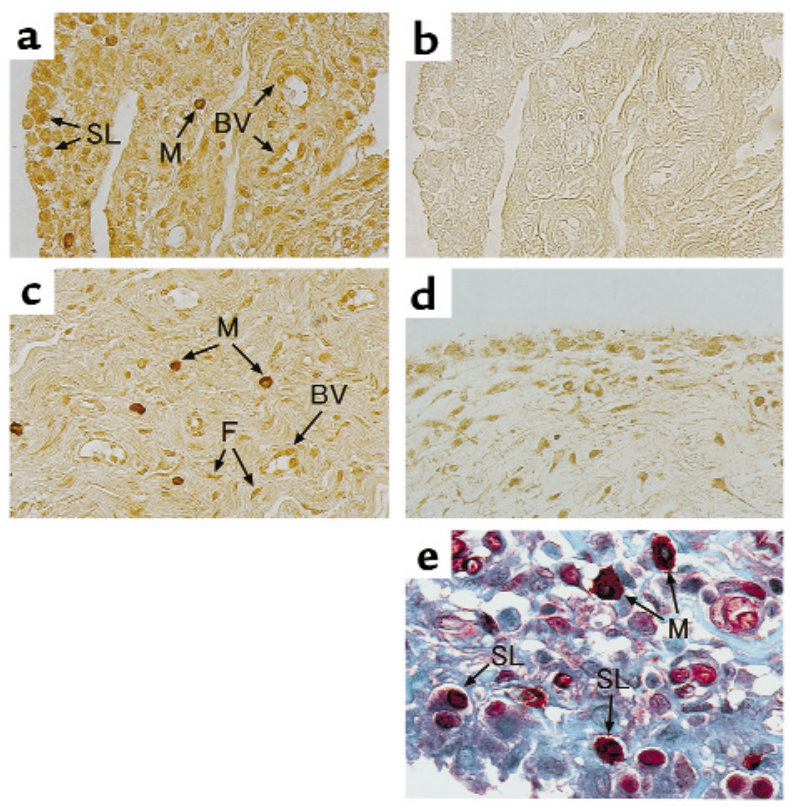

bp in all synovial tissues and cultured synoviocytes (Figure 3a). Western blot analysis was performed using PPAR- $\gamma$-specific antibody. A specific band corresponding to PPAR- $\gamma$ at a molecular size of $55 \mathrm{kDa}$ was detected in all subjects (5 of 5) and in adipose tissue (Figure 3b). Negative control with no PPAR- $\gamma$ antibody or antibody absorbed with synthetic PPAR$\gamma$ polypeptide did not yield a detectable signal.

Inhibition of synoviocyte proliferation by PPAR- $\gamma$ ligands. To investigate the effects of PPAR- $\gamma$ ligands on RA synoviocyte proliferation $(n=5)$, we analyzed cell viability in vitro by a modified MTT assay. Synoviocytes were treated with troglitazone, $15 \mathrm{~d}-\mathrm{PGJ}_{2}, \mathrm{PGE}_{2}$, and $\mathrm{PGF}_{2 \alpha}$ at concentrations of $20 \mu \mathrm{M}$. Cell counting at day 1 clearly showed a marked inhibition of synoviocyte proliferation with both troglitazone and $15 \mathrm{~d}-\mathrm{PGJ}$. In contrast, a $10-15 \%$ increase in cell proliferation was observed in synoviocytes with other PGs (Figure 4a). Suppression of
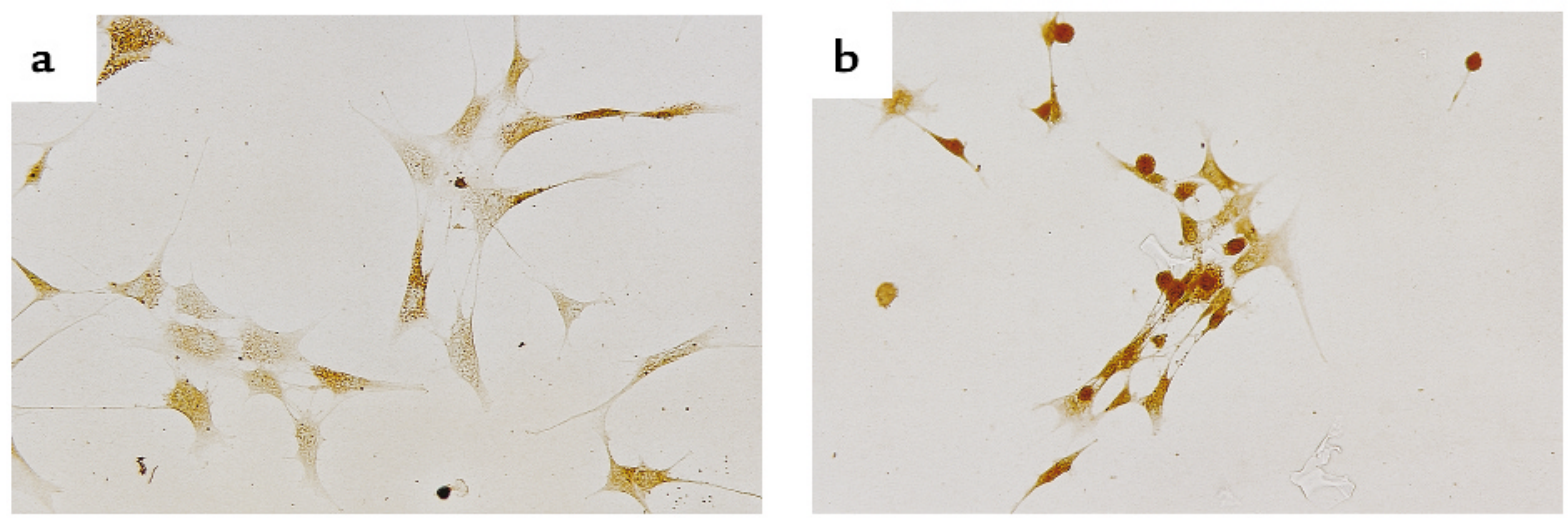

\section{Figure 2}

The expression of PPAR- $\gamma$ in cultured synoviocytes. (a) Untreated cultured synoviocytes. Synoviocytes expressed fibroblastoid morphology. Immunoreactive PPAR- $\gamma$ was localized in cytoplasmic region and nucleus, but predominantly in the cytoplasmic region in some synoviocytes. (b) Synoviocytes treated with $15 \mathrm{~d}-\mathrm{PG} \mathrm{J}_{2}(10 \mu \mathrm{M}, 12$ hours). Synoviocytes appeared less active and had an irregular or round shape, with nuclear translocation of PPAR- $\gamma . \times 100$. 
a

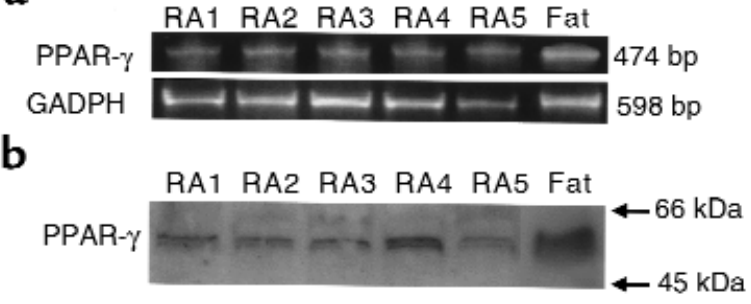

\section{Figure 3}

The expression of PPAR- $\gamma$ mRNA and protein in cultured synoviocytes. (a) Primers for PPAR- $\gamma$ generated the expected 474 nucleotide band after 40 cycles of PCR. Primers for human GAPDH generated the expected 598 bp in all subjects and fat tissue. (b) PPAR- $\gamma$ protein (55 kDa) expressed in cultured synoviocytes and fat tissue by Western blot analysis. RA 1-5, synovial tissue from patients with RA.

synoviocyte proliferation with troglitazone and $15 \mathrm{~d}$ $\mathrm{PGJ}_{2}$ was induced in a concentration-dependent manner (Figure 4, b and c). The half-maximal concentration of synoviocyte inhibition $\left(\mathrm{IC}_{50}\right)$ was approximately $5-8$ $\mu \mathrm{M}$ for $15 \mathrm{~d}_{-} \mathrm{PGJ}_{2}$ and $20 \mu \mathrm{M}$ for troglitazone. In addition, the morphologic change of cultured synoviocytes was confirmed by a microscopic analysis. Cells treated with $15 \mathrm{~d}-\mathrm{PGJ}_{2}(10 \mu \mathrm{M}, 12$ hours) appeared less active and had an irregular or round shape, with the nuclear translocation of PPAR- $\gamma$ (Figure 2b). But untreated synoviocytes maintained the characteristics of adherent fibroblasts (Figure 2a).

Induction of synovial apoptosis with PPAR- $\gamma$ ligands. To delineate whether the cell death induced with PPAR$\gamma$ ligands was the result of apoptosis or not, we evaluated the cells by assessing chromatin morphology using HOECHST staining. Synoviocytes treated with troglitazone $(40 \mu \mathrm{M})$ and $15 \mathrm{~d}-\mathrm{PGJ}_{2}(20 \mu \mathrm{M})$ showed chromatin condensation, cellular shrinkage, small membrane-bound bodies (apoptotic bodies), and cytoplasmic condensation (Figure 5, a and b). These cellular changes were typical characteristic of apoptosis. In contrast, untreated cells maintained normal chromatin patterns and cell size (Figure $5 \mathrm{c}$ ).

Intraperitoneal administration of $15 \mathrm{~d}-\mathrm{PGJ} \mathrm{J}_{2}$ ameliorated adjuvant-induced arthritis. We demonstrated the effect of $15 \mathrm{~d}-\mathrm{PGJ}_{2}$ and troglitazone on AIA in female Lewis rats. After onset of arthritis at day $7,15 \mathrm{~d}-\mathrm{PGJ}_{2}$ and troglitazone were administered intraperitoneally for several doses. Troglitazone and $15 \mathrm{~d}-\mathrm{PGJ}_{2}$ suppressed the progression of clinical arthritis dose dependently when compared with control rats treated with PBS, as demonstrated by both paw volume (Figure 6, a and c) and arthritis score (Figure 6, b and d). In 15d$\mathrm{PGJ}_{2}$-treated rats, significant effects were obtained with the dose of $1 \mathrm{mg} / \mathrm{kg} / \mathrm{day}$ at day 16-18. Especially at day 18 , joint swelling was suppressed with a dose of $1 \mathrm{mg} / \mathrm{kg} /$ day of $15 \mathrm{~d}-\mathrm{PGJ}_{2}$ (Figure 7, a and b), and both paw volume and arthritis score were significantly decreased $(P<0.01)$. In troglitazone-treated rats, significant effects were also obtained with a dose of 100 $\mathrm{mg} / \mathrm{kg} /$ day $(P<0.01 ;$ Figure $6, \mathrm{c}$ and d). In addition, at day 18 histological findings of the foot joint in both $15 \mathrm{~d}-\mathrm{PGJ}_{2}$-treated rats $(1 \mathrm{mg} / \mathrm{kg} /$ day $)$ and troglitazonetreated $(100 \mathrm{mg} / \mathrm{kg} /$ day $)$ rats, revealed that the infiltration of mononuclear cells and the formation of pannus in synovial tissues were suppressed significantly $(P$ $<0.01$; Figures 7, $\mathrm{c}$ and d, and Figure 8). These data suggest that PPAR- $\gamma$ ligands have anti-inflammatory effects and growth inhibition of synovial cells in AIA. Side effects of intraperitoneal administration of PPAR- $\gamma$ ligands. There was no mortality in either $15 \mathrm{~d}_{-} \mathrm{PGJ}_{2}$ - and troglitazone-treated rats. Troglitazone treatment significantly increased adipose tissue mass in the abdomen and dose dependently, though not to a statistically significant level, increased body weight. The liver and kidney histological examination showed no abnormalities. In $15 \mathrm{~d}-\mathrm{PGJ}_{2}$-treated rats, we could not detect any abnormal changes compared with controls.

\section{Discussion}

In the present study, we found immunoreactive PPAR$\gamma$ expressed strongly in macrophages and moderately in synovial cells, fibroblasts, and endothelial cells in synovial tissues from RA. The extent and intensity of immunoreactive PPAR- $\gamma$ of these cells in RA was greater

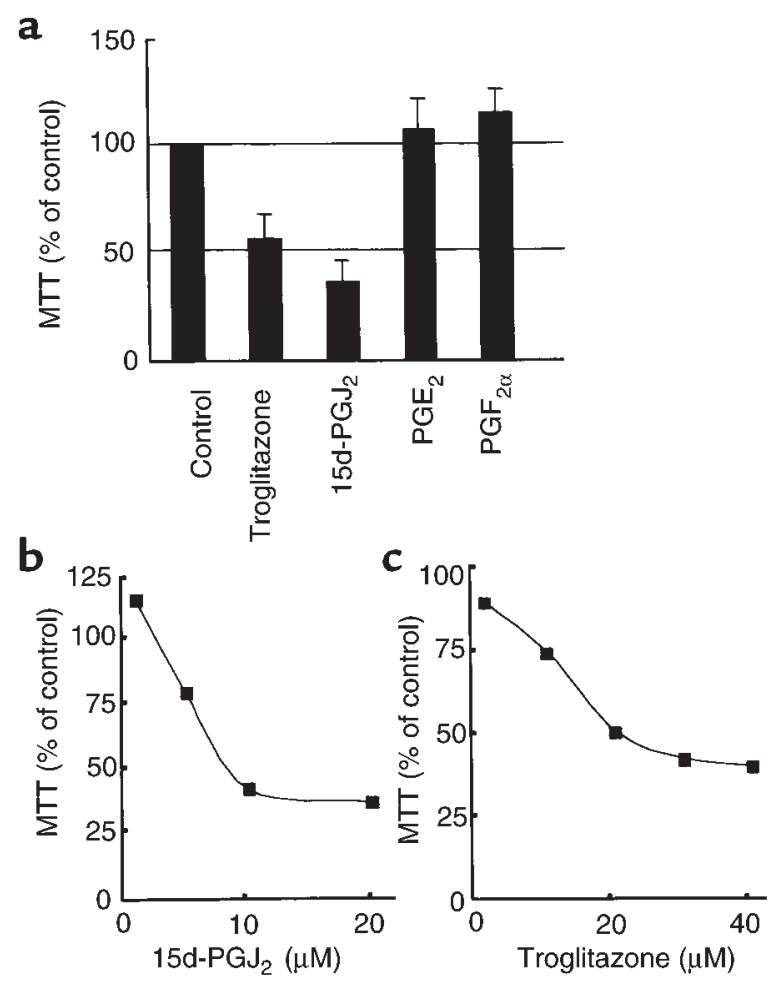

Figure 4

The expression of PPAR- $\gamma$ ligands on synoviocyte viability. Synoviocytes treated with various prostanoids $(20 \mu \mathrm{M})$, troglitazone $(20$ $\mu \mathrm{M})$, and $15 \mathrm{~d}-\mathrm{PG} \mathrm{J}_{2}(20 \mu \mathrm{M})$ for 24 hours were measured by an MTT assay $(n=5)$ and expressed as percentage of control conditions (a). The dose-response analysis of synoviocytes treated with $15 \mathrm{~d}-\mathrm{PG} \mathrm{J}_{2}(\mathbf{b})$ or troglitazone (c) was also measured by an MTT assay $(n=5)$. PPAR ligands suppressed the proliferation of synoviocyte concentration dependently. Data represent mean \pm SD. 

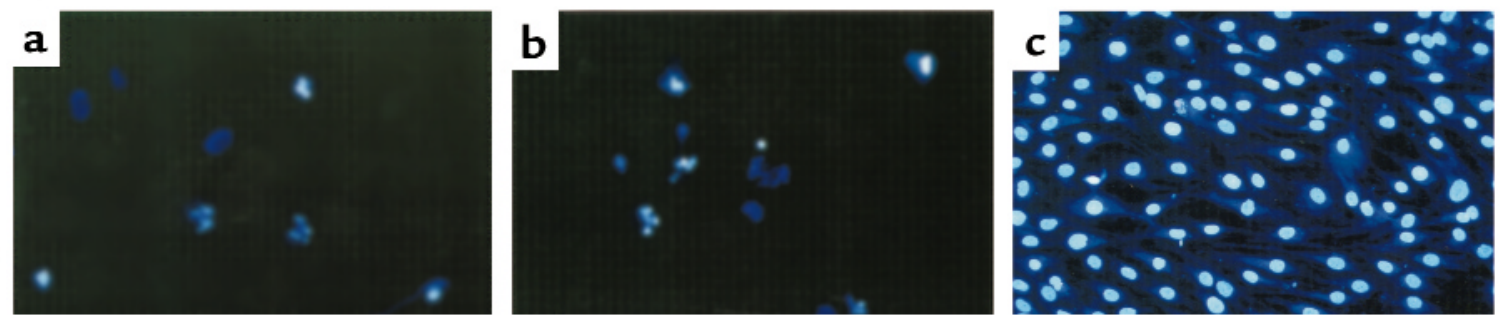

\section{Figure 5}

Fluorescence microscopic appearance of apoptotic cells by PPAR- $\gamma$ ligands. HOECHST staining was used to stain apoptotic synoviocytes treated with PPAR- $\gamma$ ligands. Synoviocytes treated with troglitazone ( $40 \mu \mathrm{M}, 24$ hours) (a) and 15d-PGJ 2 (20 $\mu \mathrm{M}, 24$ hours) (b) demonstrated typical findings of apoptosis, marked chromatin condensations, small membrane-bound bodies (apoptotic bodies), cytoplasmic condensations, and cellular shrinkage. Untreated synovial cells (c) kept a normal chromatin pattern and showed no change in a nuclear morphology. $\times 200$.

than those in OA. We also demonstrated that cultured synoviocytes from RA expressed PPAR- $\gamma$ mRNA and protein, and that PPAR- $\gamma$ ligands inhibited the growth of synoviocytes through apoptosis in vitro. Moreover, $15 \mathrm{~d}_{-} \mathrm{PGJ} \mathrm{J}_{2}$ and troglitazone were potent in suppressing chronic inflammation and pannus formation in AIA. Macrophages initiate immune/inflammatory response, and macrophage-derived cytokines mediate the synovial cell proliferation and bone destruction in RA. PPAR- $\gamma$ promotes monocyte/macrophage differentiation (45) and has anti-inflammatory properties. PPAR- $\gamma$ expression is undetectable in circulation in human monocytes, but is strongly induced in macrophage upon differentiation (29). PPAR- $\gamma$ ligands inhibit the induction of NO synthase, gelatinase $B$, and scavenger receptor $A(24)$. They also can reduce the secretion of IL-1 $1 \beta$, IL- 6 , and TNF- $\alpha$, which are key proinflammatory cytokines in RA (25). Treatment of differentiated macrophages with PPAR- $\gamma$ agonist induces apoptosis, which is more pronounced in macrophages activated with IFN- $\alpha$ and TNF- $\alpha$ (29). Recent data have shown that PPAR- $\gamma$ agonists also have immunosuppressive effects in helper T lymphocytes (23). Moreover, PPAR- $\gamma$ agonists induce apoptosis in the fibroblast (30) and endothelial cell (31), and inhibit VEGF-induced angiogenesis in rats (46). Angiogenesis is also important for pannus formation in RA (2). We found $15 \mathrm{~d}-$ $\mathrm{PGJ}_{2}$ and troglitazone inhibited the growth of the synovial cell in vitro and induced its apoptosis. These findings suggest that PPAR- $\gamma$ agonists inhibit the function of macrophages and suppress pannus formation through apoptosis of macrophages, synovial cells, and endothelial cells in RA.

$15 \mathrm{~d}-\mathrm{PGJ} \mathrm{J}_{2}$ is thought to be derived from $\mathrm{PGD}_{2}$, which is a major COX product in a variety of tissues and cells (47), and especially from the COX-1 pathway in peritoneal macrophages (48). It is likely that $\mathrm{J}_{2}$ cyclopentenone can be synthesized in vivo $(49,50)$ and that $\mathrm{PGD}_{2}$ can be converted readily to $\mathrm{PGJ}_{2}$ in the presence of plasma (51). Members of the PGJ series have been reported to have their own unique spectrum of biological effects, including the inhibition of cell cycle progression and cytokine production in macrophages, the suppression of viral replication, the induction of heat shock protein expression, and the a

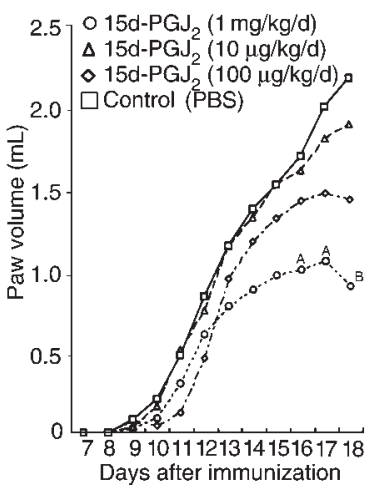

b

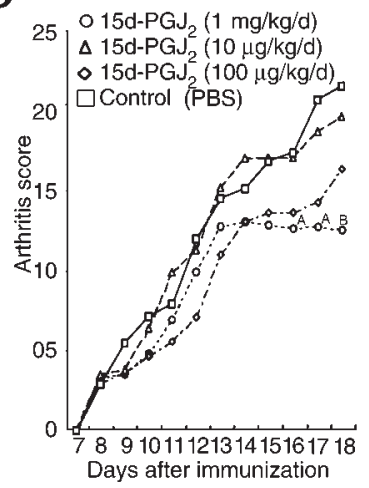

C

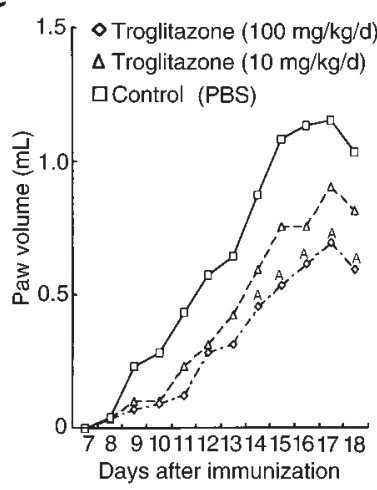

d

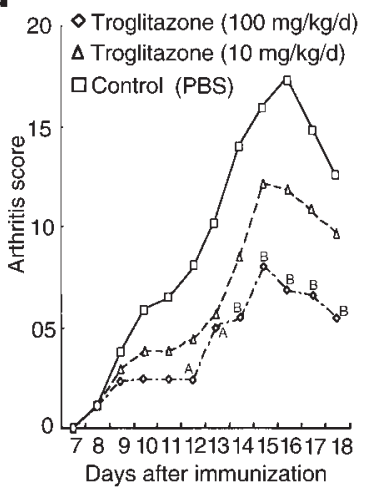

\section{Figure 6}

Suppression of clinical arthritis by $15 \mathrm{~d}-\mathrm{PG} \mathrm{J}_{2}$ and troglitazone treatment in AIA. $15 \mathrm{~d}-\mathrm{PG} \mathrm{J}_{2}$ (2 times a day) and troglitazone (once a day) were intraperitoneally administered daily in female Lewis rats after onset of arthritis, at day 7 . (a and $\mathbf{b}) 15 \mathrm{~d}-\mathrm{PG} \mathrm{J}_{2}-\mathrm{treated}$ rats, $10 \mu \mathrm{g} / \mathrm{kg} / \mathrm{d}(n=$ $8), 100 \mu \mathrm{g} / \mathrm{kg} / \mathrm{d}(n=8), 1 \mathrm{mg} / \mathrm{kg} / \mathrm{d}(n=8) ; \mathrm{PBS}(n=8)$. (c and d) Troglitazone-treated rats, $10 \mathrm{mg} / \mathrm{kg} / \mathrm{d}(n=7), 100 \mathrm{mg} / \mathrm{kg} / \mathrm{d}(n=7) ; \mathrm{PBS}$ $(n=7)$. Paw volume ( $\mathbf{a}$ and $\mathbf{c})$ and arthritis score $(\mathbf{b}$ and $\mathbf{d})$ were assessed daily after onset of arthritis. ${ }^{A} P<0.05 ; \mathrm{B} P<0.01$. 


\section{Figure 7}

Photographic and histological features of the hindlimb in AIA treated with $15 \mathrm{~d}-\mathrm{PG} 2 \mathrm{2}$ or PBS. (a and $\mathbf{c}$ ) Samples from a representative rat treated with $15 d-P G J_{2}$ in AIA. (b and $\mathbf{d}$ ) Samples from a PBStreated rat in AIA. Joint swelling of the foot in AIA was clearly reduced with $15 \mathrm{~d}-\mathrm{PG} \mathrm{J}_{2}$ administration at a dose of $1 \mathrm{mg} / \mathrm{kg} / \mathrm{d}$, at day 18 (a), compared with control (b). H\&E staining of the foot joint also revealed a marked decrease of synovial inflammatory cell infiltrate and synovial lining hyperplasia (c). In contrast, hindlimbs treated with PBS revealed typical features of arthritis such as massive inflammatory cell infiltrate, pannus, and bone destruction (d). Similar findings of photographic and histological features were observed in all rats of each group. $(\mathbf{c}) \times 25$; (d) $\times 50$.

stimulation of osteogenesis $(24,25,52)$. But, the mechanism of these effects is not well understood, and the natural site and the extent of $15 \mathrm{~d}-\mathrm{PGJ}_{2}$ production in vivo remain unclear. In our study, it is of great interest that intraperitoneal administration of $15 \mathrm{~d}-\mathrm{PGJ}_{2}$, which is an intrinsic natural PPAR- $\gamma$ ligand, suppressed the chronic inflammation in AIA in rats; however, anti-inflammatory effects of PPAR- $\gamma$ ligands have not been established in vivo. In these synovial tissues, infiltration of inflammatory cells and pannus formation were markedly decreased. In addition, immunoreactive PPAR- $\gamma$ was localized predominantly in the perinuclear legion and cytoplasm in both macrophages and cultured synoviocytes. Treatment of cultured synoviocytes with $15 \mathrm{~d}-\mathrm{PGJ}_{2}$ caused the nuclear translocation of PPAR- $\gamma$ and the induction of synoviocytes apoptosis. In fact, $\Delta^{12} \mathrm{PGJ}_{2}$ can be actively incorporated into the nucleus of cells in 10 minutes (53). Because PPAR- $\gamma$ is considered to work at the level of transcription, $15 \mathrm{~d}-\mathrm{PGJ}_{2}$-induced nuclear localization of PPAR- $\gamma$ may be an initial step in its activation; however, it is still unclear, especially in vivo, whether PPAR- $\gamma$ is activated in these cells before treatment of $15 \mathrm{~d}-\mathrm{PGJ} \mathrm{J}_{2}$. Taken together, these results suggest that the mechanism of the anti-inflammatory effects of $15 \mathrm{~d}-\mathrm{PGJ}_{2}$ in AIA can be explained, at least in part, by the activation of PPAR- $\gamma$, which leads to the apopto-
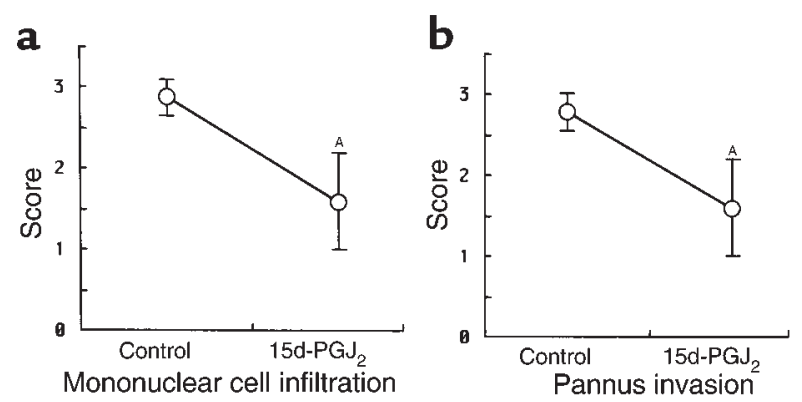
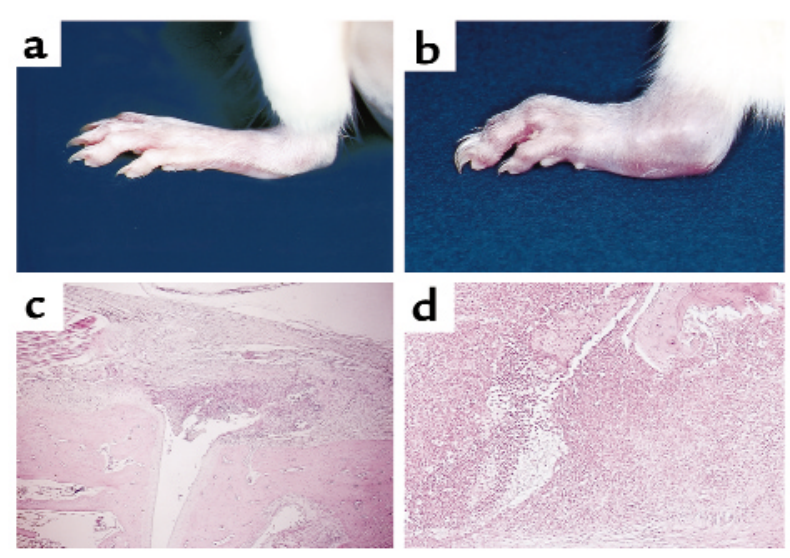

sis of several cells such as synovial cells and inhibition of macrophage function.

Troglitazone, which is a specific PPAR- $\gamma$ ligand and synthetic anti-diabetic thiazolidinedione, also suppressed the chronic inflammation and pannus formation in AIA. However, with intraperitoneal administration, a troglitazone dose of $100 \mathrm{mg} / \mathrm{kg} /$ day is required to suppress AIA to the same degree as 1 $\mathrm{mg} / \mathrm{kg} /$ day of $15 \mathrm{~d}-\mathrm{PGJ}_{2}$. These results are, however, in overall agreement with in vitro data that indicate $15 \mathrm{~d}-$ $\mathrm{PGJ}_{2}$ is $5-30$ times more potent than various thiazolidinediones, including troglitazone, at inducing synoviocyte and endothelial cell apoptosis (31) and inhibiting macrophage-derived cytokine $(24,25)$. Furthermore, $15 \mathrm{~d}-\mathrm{PGJ}_{2}$ is a direct inhibitor of IKB kinase independent of PPAR- $\gamma(54,55)$, which suggests additional anti-inflammatory effects independent of PPAR- $\gamma$. Oral administration of $500 \mathrm{mg} / \mathrm{kg} /$ day, but not $100 \mathrm{mg} / \mathrm{kg} / \mathrm{day}$, troglitazone, if started at the same time as immunization with adjuvant, also significantly suppresses AIA in rats (data not shown). In contrast, $5 \mathrm{mg} / \mathrm{kg} /$ day of troglitazone (administered orally) is required for a significant increase in insulin sensitivity, indicating at least a 100-fold-higher dose of troglitazone is required for anti-inflammatory effects. Although we cannot detect any side effects of this dose $(100 \mathrm{mg} / \mathrm{kg} /$ day, intraperitoneally) of trogli-
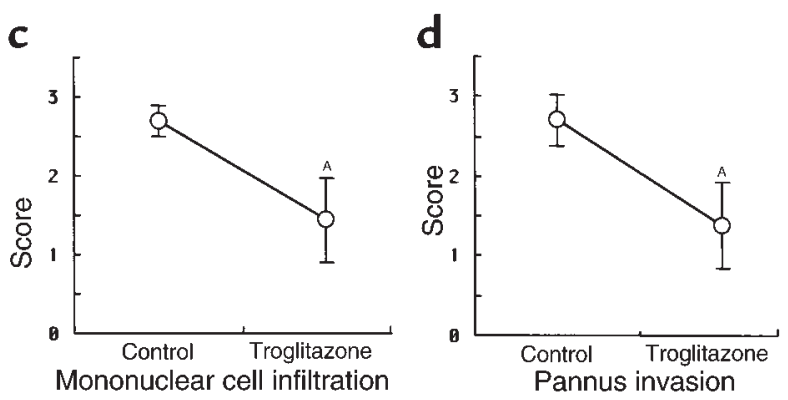

\section{Figure 8}

Histopathological scores of the hindlimb in AIA treated with $15 \mathrm{~d}-\mathrm{PGJ} \mathrm{J}_{2}$ and troglitazone. Mononuclear cell infiltration and pannus invasion into the cartilage and bone were measured by microscopic examination of the sections. ( $\mathbf{a}$ and $\mathbf{b}) 15 \mathrm{~d}-\mathrm{PG} \mathrm{J}_{2}$-treated rats at day $18(n=8)$. (c and $\mathbf{d})$ Troglitazone-treated rats at day $18(n=7)$. Data represent mean \pm SD of scores in the subsets. The differences between the subsets were statistically significant. ${ }^{A} P<0.01$. 
tazone on AIA in rats, liver toxicity has been reported in a small percentage of patients taking troglitazone (56). We should therefore carefully evaluate potential usefulness and any other side effects of new thiazolidinediones such as rosiglitazone and pioglitazone for RA treatment.

In conclusion, we demonstrate the expression of immunoreactive PPAR- $\gamma$ in macrophages and synoviocytes of the RA synovium. Furthermore, PPAR- $\gamma$ ligands inhibit the growth of synoviocytes in vitro through apoptosis. Naturally occurring PPAR- $\gamma$ ligands, especially $15 \mathrm{~d}-\mathrm{PGJ}_{2}$, had high potency in suppressing the chronic inflammation and pannus formation of AIA in rats, compared with troglitazone. These findings suggest that $15 \mathrm{~d}-\mathrm{PGJ} \mathrm{J}_{2}$ is a novel therapeutic reagent for RA, and new PPAR- $\gamma$ ligands may be potentially useful for the treatment of RA.

\section{Acknowledgments}

We thank Yoshiaki Kusaka and Toshikazu Kubo for providing the synovial samples of RA and OA and also thank Shigehiko Mukai for advice. T. Hla acknowledges the support of NIH grant HL-54710 and an established investigator award from the American Heart Association.

1. Feldmann, M., Brennan, F.M., and Maini, R.N. 1996. Rheumatoid arthritis. Cell. 85:307-310.

2. Koch, A.E. 1998. Angiogenesis: implications of rheumatoid arthritis. Arthritis Rheum. 41:951-962

3. Clancy, R.M., Amin, A.R., and Abramson, S.B. 1998. The role of nitric oxide in inflammation and immunity. Arthritis Rheum. 41:1141-1151.

4. Hopkins, S.J., and Meager, A. 1988. Cytokines in synovial fluid: II. The presence of tumour necrosis factor and interferon. Clin. Exp. Immunol. 73:88-92.

5. Fontana, A., et al. 1982. Interleukin-1 activity in the synovial fluid of patients with rheumatoid arthritis. Rheumatol. Int. 2:49-53.

6. Moreland, L.W., et al. 1997. Treatment of rheumatoid arthritis with a recombinant human tumor necrosis factor ( $\mathrm{p} 75)$-Fc fusion protein. N. Engl. J. Med. 337:141-147.

7. Elliott, M.J., et al. 1994. Randomized double-blind comparison of chimeric monoclonal antibody to tumor necrosis factor $\alpha$ (cA2) versus placebo in rheumatoid arthritis. Lancet. 344:1105-1110.

8. Campion, G.V., et al. 1996. Dose-range and dose-frequency study of recombinant human interleukin-1 receptor antagonist in patients with rheumatoid arthritis. Arthritis Rheum. 39:1092-1101.

9. Vaishnaw, A.K., Mcnally, J.D., and Elkon, K.B. 1997. Apoptosis in the rheumatic diseases. Arthritis Rheum. 40:1917-1927.

10. Fassbender, H.G., and Gay, S. 1988. Synovial processes in rheumatoid arthritis. Scand. J. Rheumatol. 76:1-7.

11. Mangelsdorf, D.J., et al. 1995. The nuclear receptor superfamily: the second decade. Cell. 83:835-839.

12. Issemann, I., and Grenn, S. 1990. Activation of a member of the steroid hormone receptor superfamily by peroxisome proliferators. Nature. 347:645-650.

13. Gearing, K.L., Gottlicher, M., Teboul, M., Widmark, E., and Gustafsson, J.-Å. 1993. Interaction of the peroxisome-proliferator-activated receptor and retinoid X receptor. Proc. Natl. Acad. Sci. USA. 90:1440-1444.

14. Kliewer, S.A., et al. 1994. Differential expression and activation of a family of murine peroxisome proliferator-activated receptors. Proc. Natl. Acad. Sci. USA. 91:7355-7359.

15. Sher, T., Yi, H.-F., McBride, O.W., and Gonzalez, F.J. 1993. cDNA cloning, chromosomal mapping, and functional characterization of the human peroxisome proliferator activated receptor. Biochemistry. 32:5598-5604.

16. Braissant, O., Foufelle, F., Scotto, C., Dauca, M., and Wahli, W. 1996. Differential expression of peroxisome proliferator-activated receptors (PPARs): tissue distribution of PPAR- $\alpha,-\beta$, and $-\gamma$ in the adult rat. Endocrinol. 137:354-366.

17. Schmidt, A., et al. 1992. Identification of a new member of the steroid hormone receptor superfamily that is activated by peroxi- some proliferator and fatty acid. Mol. Endocrinol. 6:1634-1641.

18. He, T.C., Chan, T.A., Vogelstein, B., and Kinzler, K.W. 1999. PPAR $\delta$ is an APC-regulated target of nosteroidal anti-inflammatory drugs. Cell. 99:335-345.

19. Tontonoz, P., Hu, E., and Spiegelman, B.M. 1994. Stimulation of adipogenesis in fibroblasts by PPAR $\gamma 2$, a lipid-activated transcription factor. Cell. 79:1147-1156.

20. Serhan, C.N. 1996. Inflammation. Signalling the fat controller. Nature. 384:23-24.

21. Devchand, P.R., et al. 1996. The PPAR $\alpha$-leukotriene B4 pathway to inflammation control. Nature. 384:39-43.

22. Greene, M.E., et al. 1995. Isolation of the human peroxisome proliferator-activated receptor $\gamma$ cDNA: expression in hematopoietic cells and chromosomal mapping. Gene Expr. 4:281-299.

23. Clark, R.B., et al. 2000. The nuclear receptor PPAR $\gamma$ and immunoregulation: PPAR $\gamma$ mediates inhibition of helper $\mathrm{T}$ cell responses. $J$. Immunol. 164:1364-1371.

24. Ricote, M., Li, A.C., Willson, T.M., Kelly, C.J., and Glass, C.K. 1998. The peroxisome proliferator-activated receptor- $\gamma$ is a negative regulator of macrophage activation. Nature. 391:79-82.

25. Jiang, C., Ting, A.T., and Seed, B. 1998. PPAR- $\gamma$ agonists inhibit production of monocyte inflammatory cytokines. Nature. 391:82-86.

26. Sarraf, P., et al. 1998. Differentiation and reversal of malignant changes in colon cancer through PPAR $\gamma$. Nat. Med. 4:1046-1052.

27. Kubota, T., et al. 1998. Ligand for peroxisome-proliferator activated receptor $\gamma$ (Troglitazone) has potent antitumor effect against human prostate cancer in vitro and in vivo. Cancer Res. 58:3344-3352.

28. Elstner, E., et al. 1998. Ligands for peroxisome-proliferator activated receptor $\gamma$ and retinoic acid receptor inhibit growth and induce apoptosis of human breast cancer cells in vitro and in BNX mice. Proc. Natl. Acad. Sci. USA. 95:8806-8811.

29. Chinetti, G., et al. 1998. Activation of peroxisome-activated receptor $\alpha$ and $\gamma$ induces apoptosis of human monocyte-derived macrophages. J. Biol. Chem. 273:25573-25580.

30. Altoik, S., Xu, M., and Spiegelman, B.M. 1997. PPAR $\gamma$ induces cell cycle withdrawal: inhibition of E2F/DP DNA binding activity via down-regulation of PP2A. Genes Dev. 11:1987-1998.

31. Bishop-Bailey, D., and Hla, T. 1998. Endothelial cell apoptosis induced by the peroxisome proliferator-activated receptor (PPAR) ligand 15deoxy- $\delta 12,14$-prostaglandin J2. J. Biol. Chem. 274:17042-17048.

32. Forman, B.M., Chen, J., and Evans, R.M. 1997. Hypolipidemic drugs, polyunsaturated fatty acids, and eicosanoids are ligands for peroxisome proliferator-activated receptors $\alpha$ and $\delta$. Proc. Natl. Acad. Sci. USA. 94:4312-4317.

33. Kremer, J.M., et al. 1985. Effects of manipulation of dietary fatty acids on clinical manifestations of rheumatoid arthritis. Lancet. 1:184-187.

34. Kremer, J.M., et al. 1995. Effects of high-dose fish oil on rheumatoid arthritis after stopping nonsteroidal antiinflammatory drugs. Arthritis Rheum. 38:1107-1114.

35. Lehmann, J.M., Lenhard, J.M., Oliver, B.B., Ringold, G.M., and Kliewer, S.A. 1997. Peroxisome proliferator-activated receptors $\alpha$ and $\gamma$ are activated by indomethacin and other non-steroidal anti-inflammatory drugs. J. Biol. Chem. 272:3406-3410.

36. Meade, E.A., Smith, W.L., and DeWitt, D.L. 1993. Differential inhibition of prostaglandin endoperoxide synthase (cyclooxygenase) isozymes by aspirin and other non-steroidal anti-inflammatory drugs. J. Biol. Chem. 268:6610-6614.

37. Miossec, P., and van den Berg, W. 1997. Th1/Th2 cytokine balance in arthritis. Arthritis Rheum. 40:2105-2115.

38. Huang, J.T., et al. 1999. Interleukin-4-dependent production of PPAR- $\gamma$ ligands in macrophage by $12 / 15$-lipoxygenase. Nature. 400:378-382.

39. Sano, H., et al. 1992. In vivo cyclooxygenase expression in synovial tissues of patients with rheumatoid arthritis and osteoarthritis and rats with adjuvant and streptococcal cell wall arthritis. J. Clin. Invest. 89:97-108.

40. Hashiramoto, A., et al. 1999. C-myc antisense deoxyoligonucleotide can induce apoptosis and Fas downregulation in rheumatoid synoviocyte. Arthritis Rheum. 42:954-962.

41. Auboeuf, D., et al. 1997. Tissue distribution and quantification of the expression of mRNAs of peroxisome proliferator-activated receptors and liver $\mathrm{X}$ receptor- $\alpha$ in humans: no alteration in adipose tissue of obese and NIDDM patients. Diabetes. 46:1319-1327.

42. Yamada, R., et al. 1999. Auranofin inhibits interleukin-1 $\beta$-induced transcript of cyclooxygenase-2 on cultured human synoviocytes. Eur. J. Pharmacol. 385:71-79.

43. Kawahito, Y., et al. 1998. Localization of quantitative trait loci regulating adjuvant induced arthritis: evidence for genetic factors common to multiple autoimmune diseases. J. Immunol. 161:4411-4419.

44. Taniguchi, K., et al. 1999. Induction of the $\mathrm{p} 16^{\mathrm{INK} 4 \mathrm{a}}$ senescence gene as a new therapeutic strategy for the treatment of rheumatoid arthri- 
tis. Nat. Med. 5:760-767.

45. Tontonoz, P., Nagy, L., Alvarez, J.G.A., Thomazy, V.A., and Evans, R.M. 1998. PPAR $\gamma$ promote monocyte/macrophage differentiation and uptake of oxidized LDL. Cell. 93:241-252.

46. Xin, X., Yang, S., Kowalski, J., and Gerritsen, M.E. 1999. Peroxisome proliferator-activated receptor $\gamma$ ligands are potent inhibitors of angiogenesis in vitro and in vivo. J. Biol. Chem. 274:9116-9121.

47. Giles, H., and Leff, P. 1988. The biology and pharmacology of PGD2. Prostaglandins. 35:277-300.

48. Brock, T.G., McNish, R.W., and Peters-Golden, M. 1999. Arachidonic acid is preferentially metabolized by cyclooxygenase- 2 to prostacyclin and prostaglandin E2. J. Biol. Chem. 274:11660-11666.

49. Hirata, Y., et al. 1988 . Occurrence of 9-deoxy- $\Delta 9, \Delta 12$-13,14-dihydroprostaglandin D2 in human urine. J. Biol. Chem. 263:16619-16625.

50. Gilroy, D.W., et al. 1999. Inducible cyclooxygense may have antiinflammatory properties. Nat. Med. 5:698-701.

51. Kikawa, Y., Narumitya, S., Fukusgima, M., Wakatsuka, H., and
Hayaishi, O. 1984. 9-deoxy- $\Delta^{9}, \Delta^{12}-13,14$-dihydroprostaglandin $\mathrm{D}_{2}$, a metabolite of prostaglandin $\mathrm{D}_{2}$ formed in human plasma. Proc. Natl. Acad. Sci. USA. 81:1317-1321.

52. Fukushima, M. 1992. Biological activities and mechanisms of action of $\mathrm{PGJ}_{2}$ and related compounds: an update. Prostaglandins Leukot. Essent. Fatty Acids. 47:1-12.

53. Narumiya, S., Ohno, K., Fijiwara, M., and Fukushima, M. 1986. Site and mechanism of growth inhibition by prostaglandins. II. Temperature-dependent transfer of a cyclopentenone prostaglandin to nuclei. J. Phamacol. Exp. Ther. 239:506-511.

54. Rossi, A., et al. 2000. Anti-inflammatory cyclopentenone prostaglandins are direct inhibitors of IкB kinase. Nature. 403:103-118.

55. Straus, D.S., et al. 2000. 15-Deoxy- $\delta 12,14$-prostaglandin J2 inhibits multiple steps in the NF-kB signaling pathway. Proc. Natl. Acad. Sci. USA. 97:4844-4849.

56. Imura, H. 1998. A novel antidiabetic drug, troglitazone: reason for hope and concern. N. Engl. J. Med. 338:908-909. 